\title{
OPEN Survey of rodent-borne pathogens in Singapore reveals the circulation of Leptospira spp., Seoul hantavirus, and Rickettsia typhi
}

Jane Griffiths ${ }^{1,4}$, Hui Ling Yeo ${ }^{1,4} \bowtie$, Grace Yap ${ }^{1}$, Diyar Mailepessov ${ }^{1}$, Patrik Johansson ${ }^{2}$, Hwee Teng Low ${ }^{2}$, Chern-Chiang Siew ${ }^{2}$, Patrick Lam ${ }^{3}$ \& Lee Ching Ng ${ }^{1 \bowtie}$

Rodents living alongside humans increases the probability of encounter and also the transmission of rodent-borne diseases. Singapore's cosmopolitan urban landscape provides a perfect setting to study the prevalence of four rodent-borne pathogens: Seoul hantavirus (SEOV), Leptospira species, Rickettsia typhi and Yersinia pestis, and identify the potential risk factors which may influence rodent density and transmission of rodent-borne diseases. A total of 1143 rodents were trapped from 10 unique landscape structures throughout Singapore. Real-time quantitative Polymerase Chain Reactions were used to detect pathogenic and intermediate Leptospira spp. and Yersinia pestis, whereas the seroprevalence of SEOV and $R$. typhi were analysed by Enzyme-Linked Immunosorbent Assay and Immunofluorescence Assay respectively. Multivariable logistic regression analysis was used to evaluate the association between prevalence of infection in rodent reservoirs and risk factors. Most of the rodents were caught in public residential developments (62.2\%). Among the tested rodents, $42.4 \%$ were infected with Leptospira spp., while $35.5 \%$ and $32.2 \%$ were seropositive for SEOV and $R$. typhi respectively, whereas Yersinia pestis was not detected. Furthermore, risk factors including habitat, species, gender, and weight of rodents, influenced prevalence of infection to a varying extent. This study highlights the presence of Leptospira spp., SEOV and $R$. typhi in Singapore's rodent population, suggesting the need for effective rodent management and sanitation strategies to prevent further circulation and transmission to humans.

Rodents are well-known hosts and vectors for zoonotic pathogens ${ }^{1}$ and can spread diseases through fleas, excreta and their bites ${ }^{2-4}$. Rattus norvegicus (Norway rats or sewer rats) and Rattus rattus (black or roof rats) have lived in close association with humans for thousands of years ${ }^{5,6}$. Both $R$. norvegicus and $R$. rattus are thought to have originated in $\mathrm{Asia}^{7,8}$ but today, both species can be found worldwide ${ }^{9,10}$, being introduced from continent to continent along with human migration and trade ${ }^{6,8}$. Rodents are ubiquitous and highly adapted to modified and fragmented environments ${ }^{11,12}$ and thus urbanization has facilitated a close proximity between rodents and humans, increasing the risk of human exposure to the pathogens that rodents carry ${ }^{13}$.

Singapore is a densely populated ${ }^{14}$, modern city state, with residential developments intermingled with food establishments, nature parks, commercial sites and industrial areas. Building construction and shipbuilding activities are rampant. The urban landscape provides opportunities for harbouring rodents. Commonly found species, Rattus norvegicus can be found exploiting infrastructures such as sewers systems ${ }^{15}$, false floors and burrowing under buildings and concrete ${ }^{16,17}$ while Rattus rattus, known to be agile climbers ${ }^{18}$, can be found indoors ${ }^{19}$ taking refuge in false ceilings and wall cavities ${ }^{20}$. Both species are known to be carriers of several rodent-borne zoonotic pathogens including Leptospira, hantaviruses, rickettsiae and Yersinia pestis and these pathogens are known to cause disease in humans in Southeast Asia as well as globally ${ }^{21-25}$.

Leptospirosis is a common zoonotic disease worldwide ${ }^{26}$ caused by pathogenic species of Leptospira, and both wild and urban rodents are considered to be important reservoirs ${ }^{27-29}$. In recent years, there has been an

\footnotetext{
${ }^{1}$ Environmental Health Institute, National Environment Agency, Singapore, Singapore. ${ }^{2}$ Defence Medical and Environmental Research Institute, DSO National Laboratories, Singapore, Singapore. ${ }^{3}$ SAF Biodefence Centre, Force Medical Protection Command, HO Medical Corps, Singapore Armed Forces, Singapore, Singapore. ${ }^{4}$ These authors contributed equally: Jane Griffiths and Hui Ling Yeo. ${ }^{\circledR}$ email:Yeo_Hui_Ling@nea.gov.sg; Ng_Lee_Ching@ nea.gov.sg
} 
increasing number of studies reporting the isolation of intermediate Leptospira spp., other than pathogenic Leptospira spp., from patients with symptoms consistent with leptospirosis ${ }^{30,31}$. Among the leptospirosis associated hospitalizations, patients can present a variety of flu-like symptoms such as fever, headache and chills to more severe symptoms, including kidney or liver failure and meningitis, with a $4-22 \%$ case fatality rate in cases with severe clinical illness ${ }^{32-34}$. An evaluation of the leptospirosis data collected between $2012-2015$ by the Ministry of Health, Singapore, reported that there were 165 cases, of which $60 \%$ were locally acquired ${ }^{35}$. The occupational risk of leptospirosis infection was previously reported by Chan et al. in abattoir workers, cleaners and sewer workers ${ }^{36,37}$.

Hantaviruses have been estimated to have caused 60,000-150,000 cases of human haemorrhagic fever with renal syndrome (HFRS) worldwide, annually ${ }^{38}$. There are at least 22 hantaviruses known to be pathogenic to humans $^{22}$ and various rodent species can act as a reservoir ${ }^{39,40}$, including common urban rodents found in Singapore ${ }^{25}$. Seoul hantavirus (SEOV) was reported to be carried by Rattus norvegicus and Rattus rattus, and is believed to cause milder disease than other hantaviruses in human host, leading to diagnostic challenge ${ }^{41,42}$. Hantavirus HFRS has previously, but rarely, been reported in Singapore ${ }^{43,44}$. Serological studies done in the late 1980 s on wild rats as well as patients suspected of having dengue, leptospirosis or hepatitis revealed $26 \%(37 / 142)$ of rodents and $3.8 \%(32 / 836)$ of human patients were seropositive to hantavirus using immunofluorescence assay (IFA) ${ }^{25}$. Occupational risk groups for hantaviruses include forestry workers, construction workers ${ }^{45}$, and farmers ${ }^{39}$.

Rickettsia typhi, the causative agent of murine typhus, is known to cause a relatively mild febrile disease in humans but complications can arise resulting in death ${ }^{46,47}$. Infected rodents serve as an amplifying host for the bacteria, and the Oriental rat flea (Xenopsylla cheopis) acts as the main vector responsible for the transmission to humans ${ }^{48-50}$. In Singapore, murine typhus cases ranged annually between 19-128 human cases between the years $1999-2003^{51}$. Both occupational and domestic exposure to rodents has been highlighted in local case studies $^{52}$, and construction workers and their living quarters are also commonly associated with this disease ${ }^{52,53}$.

Plague, a disease caused by an infection with the bacteria, Yersinia pestis, is a severe disease with a case fatality rate between $30-100 \%$ if left untreated ${ }^{54}$. Outbreaks of plague still occur in parts of the world, particularly Madagascar ${ }^{55}$, but there have been no reports in Singapore. In endemic areas, plague can be found circulating in the rodent population, while infected fleas serving as the main vector is involved in the transmission of $Y$. pestis to new rodent host or jumping to human host ${ }^{56}$.

While plague can cause severe life-threatening diseases, infections caused by HFRS-related hantaviruses, leptospirosis and murine typhus infections can range from mild and self-limiting diseases to acute, life-threatening diseases. Furthermore, these diseases often exhibit non-specific symptoms (including high fever, myalgia, headache, thrombocytopenia, rash, abdominal pain, nausea, malaise, anorexia and jaundice), making it difficult to differentiate between these and many other diseases ${ }^{26,57-61}$.

A study was conducted to assess the prevalence of these four rodent-borne pathogens in Singapore's rodent population, and to analyse the characteristics of rodents, including habitat, weight, gender and rodent species, and their association with the prevalence of infection with the pathogens described above. This information may highlight areas of concern for public health in occupational and domestic situations, and for tailoring sanitation and rodent intervention strategies.

\section{Methods}

Ethics statement. All protocols were carried out according to relevant ARRIVE (Animal Research: Reporting of In Vivo Experiments) guidelines and regulations. Animal work was approved by Defence Science Organisation (DSO) National Laboratories Institutional Animal Care and Use Committee (DSO/IACUC/05/13) and performed in compliance with the National Advisory Committee for Laboratory Animal Research (NACLAR) Guidelines, Singapore.

Study area and rodent sampling. Singapore is a densely populated island city-state in Southeast Asia with 7810 people per square kilometres. It has a tropical rainforest climate with warm temperatures, high humidity, and abundant rainfall, with little variation throughout the year. Rodent sampling took place between January 2006 and March 2008.

Live rodents were either obtained via opportunistic sampling conducted by pest control professionals registered with the Singapore Pest Management Association or from the research teams own trapping throughout Singapore. Trap locations were selected based on rodent related reports provided by the town councils, who are responsible for the management and maintenance of the common property.

Metal single-capture live traps were baited with barbequed dried cuttlefish and apple and placed at each trap location where there were reported signs of rodent activity. Traps were left overnight and checked the following morning. Rodents were brought back to the laboratory to be sampled within the same day. Traps were deployed for 1-2 weeks at each trap location due to low trap rate caused by either avoidance of the traps or reduction in rodent population as a result of active trapping.

Rodents were euthanized with carbon dioxide. Blood samples were collected by cardiac puncture and the resulting sera were kept at $-20{ }^{\circ} \mathrm{C}$ until serological analysis. Location of capture, species (according to external morphology), body length, weight and sex of each captured animal were recorded. Spleen and kidney tissues were collected using aseptic techniques and kept frozen at $-80^{\circ} \mathrm{C}$ until DNA extraction.

Sampling locations. Rodents' urban habitats were categorized according to the features of the urban built environment such as landscape structure and variations in land use. Rodents were sampled from 10 unique 
landscape structures, spanning over 14 town councils of the total 16 town councils in Singapore. The following classifications were used:

Army Camps- a place for military training, where three to four-storey low rise buildings with living quarters, are surrounded by large green areas and vegetation. Living quarters are usually without air-conditioning, and are equipped with basic amenities such as canteen, communal dining, laundry, sanitary and bathing facilities.

Commercial sites- shophouses are generally two to three-storeys in height. The ground floor has been designed to accommodate commercial enterprises (non-food businesses), while the upper floors are usually intended for residential use.

Construction sites- premises with ongoing construction activities, construction temporary quarters (CTQs) with communal facilities (e.g. cooking, laundry, sanitary and bathing facilities) may be present to house workers of the site. Maximum occupancy of CTQ ranges from 6 to 300 workers, depending on the nature of the projects.

Food establishments- places selling fresh ingredients or prepared foods including restaurants, wet markets and hawker/food centres. Wet markets and food centres are usually one to two-storeys open-air complexes, with some housing as many as 200 vendors.

Industrial areas- premises include factories and warehouses for manufacturing purposes, usually with a nuisance buffer from residential areas. Staff canteens are available within industrial developments to primarily serve workers during breaks.

Parks- large green areas with vegetation. Bins are located at designated points around the park, with a scheduled waste collection service.

Residential-private- include landed and cluster houses, usually one or two-storeys in height, and condominiums. Usually surrounded by green areas with vegetation.

Residential- public- high-rise and high-density public housing managed by Housing Development Board (HDB). These buildings are generally ten to forty-storeys in height, with a centralised refuse chute leading to a large collection bin on the ground floor of each building. Manholes on the ground floor serve as access points for maintenance of building's sewer pipes.

Schools- institutional buildings, usually four-storeys in height, surrounded by green areas such as gardens and grass fields with running tracks. Canteens have around ten food stalls, where food is prepared and sold during lunch breaks.

Shipyards- a place for shipbuilding and ship repair activities. Sites are near the sea to allow easy access for the ships.

Rodent speciation. Species-specific Restriction Fragment Length Polymorphism (RFLP) analysis. DNA was extracted from $25 \mathrm{mg}$ of kidneys using the DNeasy tissue kit (QIAGEN, Germany) according to the manufacturer's instructions. Extracted DNAs were subjected to Polymerase Chain Reaction (PCR) using primers EGL3 and EGL4 to amplify the entire D-loop containing region of the mitochondrial DNA ${ }^{62,63}$ for rodent species identification. Each PCR reaction contained $5.0 \mu$ of a prepared primer mix (with final concentration of each primer being $1 \mathrm{mM}), 1.0 \mu \mathrm{l}$ DNA template, $1.0 \mu \mathrm{MgCl}_{2}(50 \mathrm{mM}), 0.25 \mu \mathrm{l}$ dNTPs $(100 \mathrm{mM}), 0.1 \mu \mathrm{l}$ Taq DNA polymerase ( $5 \mathrm{U} / \mu \mathrm{l}$; Thermo Fisher Scientific, USA), $2.5 \mu \mathrm{l} 10 \times$ Taq Buffer and water to a final volume of $25 \mu \mathrm{l}$. The PCR reactions were performed using Biometra T-gradient (Biometra, USA) with an initial holding temperature of 94 ${ }^{\circ} \mathrm{C}$ for $60 \mathrm{~s}$, followed by 35 cycles of $94^{\circ} \mathrm{C}$ for $45 \mathrm{~s}, 60^{\circ} \mathrm{C}$ for $60 \mathrm{~s}$ and $72{ }^{\circ} \mathrm{C}$ for $60 \mathrm{~s}$, and 1 cycle of $5 \mathrm{~min}$ at $72{ }^{\circ} \mathrm{C}$.

Half of the resulting PCR-reaction was transferred to a new tube for digestion with the DNA restriction enzymes HaeIII (10 U) and DdeI (1.25 U) (Vivantis, Malaysia) and was incubated at $37^{\circ} \mathrm{C}$ overnight. $10 \mu \mathrm{l}$ of both digested and non-digested PCR-reaction were analysed on a 1.5\% agarose gel stained with ethidium bromide and visualised under UV. The expected fragment sizes for the various Rattus spp. were as follows: Rattus norvegicus (376 base pairs (bp), 443 bp), Rattus rattus (183 bp, 301 bp, 391 bp) and Rattus exulans (376 bp, 575 bp) $)^{62}$.

PCR of animal cytochrome b gene for Rattus spp. identification. Samples identified as non- Rattus norvegicus using the RFLP-method were subjected to further PCR and sequencing of the mitochondrial cytochrome $b$ $(c y t b)$ gene to discriminate between closely related Rattus species. The PCR and sequencing of $c y t b$ gene were performed using primers mcytbHb (5'-GAATGGGAGAATGAAGTGGAATGCG-3') and mcytb1 (5'-CCA TCGTTGTAATTCAACTATAG-3') ${ }^{8}$. Each PCR reaction contained $1.5 \mu \mathrm{l}$ of a prepared primer mix (with final concentrations of each primer being $2.5 \mu \mathrm{M}$ ), $1.5 \mu$ l extracted DNA from kidneys, $15 \mu \mathrm{l} 2 \times$ SYBR green master mix (Roche, Switzerland) and water to a final volume of $30 \mu \mathrm{l}$. The PCR reactions were performed and analysed using LightCycler 2.0 (Roche, Switzerland), with an initial holding temperature of $95^{\circ} \mathrm{C}$ for $1 \mathrm{~min}$, followed by 30 cycles of $95^{\circ} \mathrm{C}$ for $30 \mathrm{~s}, 55^{\circ} \mathrm{C}$ for $45 \mathrm{~s}$ and $72{ }^{\circ} \mathrm{C}$ for $1 \mathrm{~min}$, and $1 \mathrm{cycle}$ of $10 \mathrm{~min}$ at $72{ }^{\circ} \mathrm{C}$. Obtained PCR amplicons were purified using QIAquick PCR Purification Kit (QIAGEN, Germany) and sequenced using both the PCR amplification primers. The resulting DNA sequencing chromatogram were assembled using SeqMan Pro (DNASTAR Lasergene, USA). The sequences derived was aligned against the $c y t b$ gene sequence entries in GenBank using the online BLAST search engine of the National Center for Biotechnology Information (NCBI) to detect sequences with high similarity for species identification.

Pathogenic and intermediate Leptospira spp. DNA detection using specific PCR. A real-time quantitative PCR previously described by Smythe LD et al. ${ }^{64}$ was used for the detection of pathogenic and intermediate Leptospira spp.. Briefly, forward primers LeptoF (5' - CCCGCGTCCGATTAG - 3') and reverse LeptoR (5' - TCCATTGTGGCCGRACAC - 3') with probe (5' FAM -CTCACCAAGGCGACGATCGGTAGC - 3' TAMRA) were used to target a partial sequence of the $r r s$ (16S) gene, that is present in both pathogenic and intermediate Leptospira spp. ${ }^{65}$. Real-time PCR assay was adapted to suit the LightCycler 2.0 system (Roche, Switzerland). Each PCR reaction consisted of $0.6 \mu \mathrm{l}$ of a prepared primers and probe mix (with final concentrations 
of each primer/probe being $0.2 \mu \mathrm{M}$ ), $5.0 \mu \mathrm{l}$ extracted DNA from kidneys, $2.0 \mu \mathrm{l} 5 \times$ LightCycler Multiplex DNA master mix (Roche, Switzerland) and water to a final volume of $10 \mu \mathrm{l}$. The PCR reactions were performed and analysed using LightCycler 2.0 (Roche, Switzerland), with an initial holding temperature of $95^{\circ} \mathrm{C}$ for $2 \mathrm{~min}$, followed by 55 cycles of $94^{\circ} \mathrm{C}$ for $10 \mathrm{~s}$ and $60^{\circ} \mathrm{C}$ for $60 \mathrm{~s}$, and 1 cycle of $20 \mathrm{~s}$ at $40^{\circ} \mathrm{C}$. A negative result was assigned where no amplification occurred when threshold cycle $(\mathrm{Ct})$ value was greater than 40 cycles.

Serology assay for Seoul hantavirus. An Enzyme-Linked Immunosorbent Assay (ELISA) was performed on rodent sera as previously described ${ }^{66}$, for the detection of hantavirus-specific antibodies using a recombinant peptide antigen consisting of the $120 \mathrm{~N}$-terminal amino acids of Seoul hantavirus nucleocapsid (N) produced in E. coli (obtained from Dr Göran Bucht) ${ }^{67}$. Briefly, high binding ELISA 96-well plates (Nunc, Thermo Fisher Scientific, USA) were coated with $50 \mu \mathrm{l}$ of $1 \mu \mathrm{g} / \mathrm{ml}$ truncated Seoul hantavirus nucleocapsid protein in coating buffer $\left(0.015 \mathrm{M} \mathrm{Na}_{2} \mathrm{CO}_{3}, 0.034 \mathrm{M} \mathrm{NaHCO}_{3}, \mathrm{pH} 9.6\right)$, for $2 \mathrm{~h}$ at $37{ }^{\circ} \mathrm{C}$ or overnight at $4{ }^{\circ} \mathrm{C}$. The plates were blocked with $350 \mu \mathrm{l}$ of $5 \%$ skim milk in Phosphate Buffered Saline (PBS), pH 7.4, for $1 \mathrm{~h}$ at $37{ }^{\circ} \mathrm{C}$. Rodent sera were diluted 1:200 in PBS with 3\% skim milk before $50 \mu$ of each sample was added into each well and incubated for $2 \mathrm{~h}$ at $37{ }^{\circ} \mathrm{C}$. The plates were washed twice with PBST (PBS supplemented with $0.05 \%$ Tween-20; Thermo Fisher Scientific, USA) and once with PBS. $50 \mu \mathrm{l}$ of 1:10,000 dilution of HRP-labelled goat anti-rat (Pierce Biotechnology, Thermo Fisher Scientific, USA ) was added into each well and incubated $1 \mathrm{~h}$ at $37{ }^{\circ} \mathrm{C}$. Plates were washed as previously described and $100 \mu \mathrm{l}$ of TMB One Solution (Promega, USA) was added and the reaction was stopped after 15 min using $100 \mu \mathrm{l} 2 \mathrm{M} \mathrm{H}_{2} \mathrm{SO}_{4}$. The plates were read at $450 \mathrm{~nm}$ in an ELISA plate reader.

Immunofluorescence assay for detecting Rickettsia typhi IgG antibodies. Indirect Immunofluorescence Assay (IFA) is the golden standard for serodiagnosis of murine typhus. Preparation of the IFA slides and the IFA tests were done according to Bozeman FM et al. ${ }^{68}$. Rickettsia typhi (Wilmington strain) was grown in the Biosafety Level 3 laboratory. Briefly, $2 \mu$ of substrate antigens (105 PFU/ml) were spotted on each well. The slides were air-dried and fixed with $80 \%$ acetone and frozen until usage. Rodent sera were diluted at least 1:64 in $2 \%$ Casein buffer (Sigma-Aldrich, USA), and $2 \mu$ of each sample were spotted onto the slides. $R$. typhi positive controls and negative controls were included on each slide. Slides were incubated in a humidifier at $37{ }^{\circ} \mathrm{C}$ for $30 \mathrm{~min}$. Goat anti-rat IgG conjugated to FITC (Chemicon, Merck, USA) was used as a detection antibody. The slides were further incubated at $37{ }^{\circ} \mathrm{C}$ for $30 \mathrm{~min}$ before being read using a fluorescence microscope. Fluorescence detected in rodent sera at 1:128 dilution was considered positive for $R$. typhi IgG antibodies.

Yersinia pestis DNA detection using specific PCR. DNA was extracted from $10 \mathrm{mg}$ of spleen using the DNeasy tissue kit (QIAGEN, Germany) according to manufacturer's instructions. Extracted DNAs were subjected to real-time quantitative PCR for the detection of Yersinia pestis ${ }^{69}$. The real-time PCR assay was adapted to suit the LightCycler 2.0 system (Roche, Switzerland). Briefly, forward primers YP3a (5' - TGTAGCCGC TAAGCACTACCATCC - 3') and reverse YP3a (5' - GGCAACAGCTCAACACCTTTGG - 3') with probe (5' FAM - TCAAGGTTATTGACGGTATCGAGTAGGGT - 3' TAMRA) were used. Each PCR reaction consisted of $0.3 \mu \mathrm{l}$ of a prepared primer mix (with final concentrations of each primer being $0.3 \mu \mathrm{M}$ ), $0.2 \mu \mathrm{l}$ probe (final concentration of $0.2 \mu \mathrm{M}$ ), and $1.0 \mu \mathrm{l}$ of extracted DNA, $2.0 \mu \mathrm{l} 5 \times$ LightCycler Multiplex DNA master mix (Roche, Switzerland) and water to a final volume of $10 \mu \mathrm{l}$. The PCR reactions were performed and analysed using LightCycler 2.0 (Roche, Switzerland), with an initial holding temperature of $95^{\circ} \mathrm{C}$ for $1 \mathrm{~min}$, followed by 55 cycles of $94^{\circ} \mathrm{C}$ for $5 \mathrm{~s}, 60^{\circ} \mathrm{C}$ for $5 \mathrm{~s}$ and $72^{\circ} \mathrm{C}$ for $1 \mathrm{~min}$, and 1 cycle of $30 \mathrm{~s}$ at $40^{\circ} \mathrm{C}$. A negative result was assigned where no amplification occurred when threshold cycle $(\mathrm{Ct})$ value was greater than 40 cycles.

Statistical analysis. To investigate the relationship between positive binary outcomes for Leptospira spp. PCR, Seoul hantavirus ELISA and Rickettsia typhi IFA and characteristics of rodents, three separate multivariable logistic regression models were built. The following variables were considered: the landscape structures where the rodents were trapped, species of the rodent, weight, and sex. As described above, there were 10 landscape structures: residential- public, residential- private, food establishments, construction sites, industrial areas, commercial sites, schools, army camps, parks and shipyards. Weight was coded as continuous variable, and the rest of the independent variables as categorical.

For each outcome, bivariable logistic regression analysis was first conducted to ascertain the significant association of the variable and the outcome. The bivariate analysis for the weight of rodents was restricted to species as $R$. rattus and $R$. norvegicus differ in size ${ }^{70}$. Subsequently, to avoid confounding between the explanatory variables and the outcome, multivariable logistic regression models for each outcome were built. Statistically significant variables with lowest $p$-values were added into the multivariable regression model first. The model was re-fitted after addition of each new variable. The retention of the variables in the model was justified if the variables remained statistically significant and the Akaike's Information Criterion value for the new model was lower compared to the model without the new variable ${ }^{71}$. Statistically significant cut off was set at 0.05 . Since the weight differs between $R$. rattus and $R$. norvegicus, the interaction between weight and species was also investigated in the multivariable logistic regression model. The collinearity between the independent variables in all three regression models was assessed with the Generalised Variance Inflation Factor $\left(\mathrm{GVIF}^{1 /\left[2^{*} d f\right]}\right)^{72}$. Variables with values of GVIF exceeding threshold of 2 were removed from the final model ${ }^{73}$.

The analysis was conducted using R software version 3.6.3. Only complete observations were included in the final multivariable logistic regression models for each pathogen outcome. Multivariable logistic regression models with positive Leptospira spp. PCR outcome, Seoul hantavirus and Rickettsia typhi seropositive outcomes as dependent variables, had 1125, 1093 and 1114 complete observations respectively. 


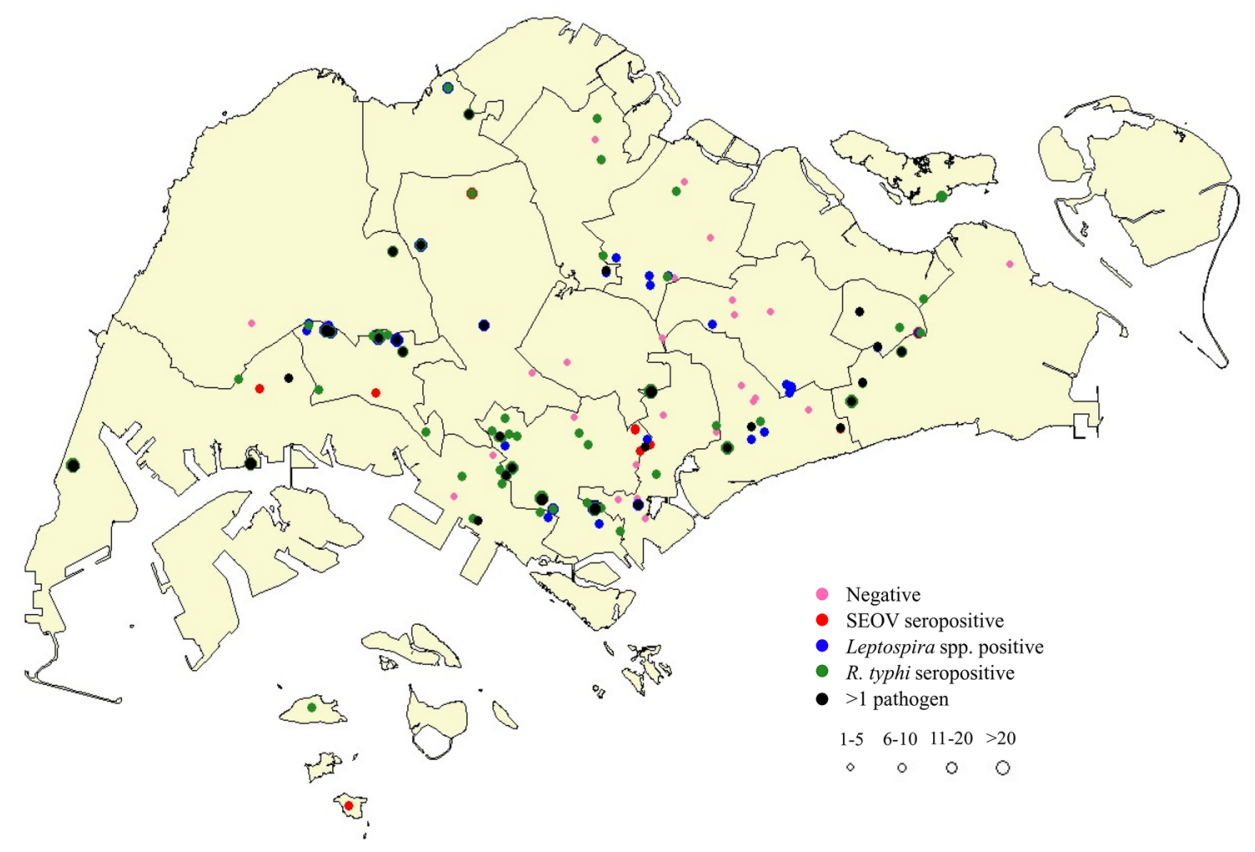

Figure 1. Spatial distribution of rodent trappings and prevalence of pathogens in $R$. norvegicus and $R$. rattus in Singapore, 2006-2008. Demarcations represent town councils. $\bigcirc$ : rodents with no infection; $\bigcirc$ : rodents seropositive for SEOV; : rodents positive for Leptospira spp.; : rodents seropositive for R. typhi; : rodents positive for more than one type of pathogen. The number of rodents trapped was reflected by the size of the circle. Abbreviations: SEOV, Seoul hantavirus. Map created using the Free and Open Source QGIS. QGIS.org, 2021. QGIS 2.18.25. Geographic Information System. QGIS Association. http://www.qgis.org.

\section{Results}

Trapped rodents according to their species and trapping sites. Throughout Singapore, a total of 1143 rodents were trapped over a 2 -year 2-month period. These rodents were trapped from 10 unique landscape structures, spanning over 14 town councils of the total 16 town councils in Singapore (Fig. 1). Species identification of 1143 rodents was done by sequencing, resulting in the identification of Rattus norvegicus $(n=990)$, Rattus rattus ( $n=136)$, Rattus tiomanicus $(n=13)$, Rattus exulans $(n=3)$ and Rattus tanezumi $(n=1)$. Two species, Rattus norvegicus and Rattus rattus, were selected for further analysis, as other species were present in low numbers.

Rodents were trapped in the following landscape structures: Residential- public $(n=700)$, Residential- private $(n=25)$, Food establishments $(n=76)$, Construction sites $(n=44)$, Industrial areas $(n=47)$, Commercial sites $(n=118)$, Schools $(n=10)$, Army Camps $(n=46)$, Parks $(n=35)$, Shipyards $(n=25)$ (Table 1$)$.

Pathogenic and intermediate Leptospira spp.. The general prevalence of Leptospira spp. in tested rodents was $42.4 \%$, with a higher prevalence observed in $R$. norvegicus (46.8\%) compared with $R$. rattus (10.4\%). The lowest prevalence of Leptospira spp. was found to be in schools $(0.0 \%)$ and the highest prevalence to be in industrial areas (53.2\%). In bivariate analyses, Leptospira spp. infection was associated with landscape structure, species, sex and weight of rodents (Table 2). Rodents captured in army camps (OR=0.19, 95\% CI: 0.08-0.40), construction sites $(\mathrm{OR}=0.10,95 \% \mathrm{CI}: 0.03-0.26)$, food establishments $(\mathrm{OR}=0.47,95 \% \mathrm{CI}$ : 0.28 to 0.78 , parks $(\mathrm{OR}=0.17,95 \% \mathrm{CI}: 0.06-0.41)$ and private residential developments $(\mathrm{OR}=0.20,95 \% \mathrm{CI}: 0.06-0.52)$ showed a reduced prevalence of infection when compared with public residential developments (Table 2). $R$. norvegicus had 7.06 times ( $\mathrm{OR}=7.06,95 \% \mathrm{CI}$ : 4.20-12.7) higher likelihood than $R$. rattus to be infected, whereas female rodents were 1.38 times $(\mathrm{OR}=1.38,95 \% \mathrm{CI}: 1.09-1.76)$ more likely than male rodents to be infected. The prevalence of Leptospira spp. infection increases for every $1 \mathrm{~g}$ increase in body weight for both $R$. rattus $(\mathrm{OR}=1.03$, 95\% CI: 1.01-1.05) and R. norvegicus (OR=1.009, 95\% CI: 1.008-1.011) (Table 2).

Multivariable logistic regression model for rodents with positive Leptospira spp. PCR outcome (Table 3) included the following three variables that were found to be statistically significant $(P<0.05)$ in the bivariate analysis: landscape structure, weight, and sex. Although the association between species of rodents and Leptospira spp. infection was statistically significant in the bivariate analysis, it was not included in the multivariate model due to collinearity (VIF > 2.0). Landscape structure, adjusted for weight and sex, was a statistically significant factor associated with Leptospira spp. infection in captured rodents. Prevalence of infection was increased in rodents captured in commercial sites $(\mathrm{AOR}=2.91,95 \% \mathrm{CI}: 1.82-4.68)$, whereas rodents captured in army camps $(\mathrm{AOR}=0.33,95 \% \mathrm{CI}: 0.12-0.76)$, construction sites $(\mathrm{AOR}=0.19,95 \% \mathrm{CI}: 0.05-0.54)$ and parks $(\mathrm{AOR}=0.18,95 \%$ CI: 0.04-0.53) showed a reduced prevalence when compared with public residential developments (Table 3). Leptospira spp. infection was also independently associated with weight and sex of rodents. The prevalence of Leptospira spp. infection increases for every $1 \mathrm{~g}$ increase in body weight (AOR $=1.010,95 \% \mathrm{CI}$ : 1.009-1.012), 


\begin{tabular}{|l|l|l|}
\hline Variable & Rattus norvegicus & Rattus rattus \\
\hline Landscape structure & \multicolumn{2}{l|}{} \\
\hline Army camps & 8 & 38 \\
\hline Commercial sites & 117 & 1 \\
\hline Construction sites & 24 & 20 \\
\hline Food establishments & 76 & 0 \\
\hline Industrial areas & 41 & 6 \\
\hline Parks & 8 & 27 \\
\hline Residential- private & 16 & 9 \\
\hline Residential- public & 699 & 1 \\
\hline Schools & 1 & 9 \\
\hline Shipyards & 0 & 25 \\
\hline Total number & 990 & 136 \\
\hline Sex & & \multicolumn{2}{|l|}{} \\
\hline Male & $441(44.6 \%)^{*}$ & $63(46.3 \%)^{*}$ \\
\hline Female & $530(53.5 \%)^{*}$ & $71(52.2 \%)^{*}$ \\
\hline Mean body weight (g) & 187.93 & 112.37 \\
\hline
\end{tabular}

Table 1. Distribution of the captured Rattus rattus and Rattus norvegicus across the urban landscape and basic characteristics of the rodents. ${ }^{*}$ Some rodents have incomplete data; sex of rodents was not determined for 19 Rattus norvegicus and 2 Rattus rattus.

\begin{tabular}{|c|c|c|c|}
\hline Explanatory variables & Odds Ratio & $95 \%$ Conf. interval a $^{\text {a }}$ & $p$-value \\
\hline \multicolumn{4}{|l|}{ Landscape structure } \\
\hline Residential- public ${ }^{\mathrm{b}}$ & Ref & - & - \\
\hline Army camps & 0.19 & $0.08,0.40$ & $<0.001$ \\
\hline Commercial sites & 0.81 & $0.55,1.20$ & 0.3 \\
\hline Construction sites & 0.10 & $0.03,0.26$ & $<0.001$ \\
\hline Food establishments & 0.47 & $0.28,0.78$ & 0.004 \\
\hline Industrial areas & 1.17 & $0.65,2.13$ & $\begin{array}{ll}0.6 \\
\end{array}$ \\
\hline Parks & 0.17 & $0.06,0.41$ & $<0.001$ \\
\hline Residential- private & 0.20 & $0.06,0.52$ & 0.003 \\
\hline Schools ${ }^{c}$ & - & - & - \\
\hline Shipyards & 0.81 & $0.35,1.80$ & 0.6 \\
\hline \multicolumn{4}{|l|}{ Species } \\
\hline Rattus rattus ${ }^{\mathrm{b}}$ & Ref & - & - \\
\hline Rattus norvegicus & 7.06 & $4.20,12.7$ & $<0.001$ \\
\hline \multicolumn{4}{|l|}{ Sex } \\
\hline Male $^{\text {b }}$ & Ref & - & - \\
\hline Female & 1.38 & $1.09,1.76$ & 0.008 \\
\hline \multicolumn{4}{|l|}{ Weight (g) } \\
\hline Rattus rattus & 1.03 & $1.01,1.05$ & $<0.001$ \\
\hline Rattus norvegicus & 1.009 & $1.008,1.011$ & $<0.001$ \\
\hline
\end{tabular}

Table 2. Bivariable logistic regression analysis for Leptospira spp. detection in Rattus rattus and Rattus norvegicus. Significant values $(P<0.05)$ are shown in bold. ${ }^{\text {a }} 95 \%$ Confidence Interval. ${ }^{b}$ Reference category. ${ }^{\mathrm{c}}$ Omitted from the model because no Leptospira infection was detected at this site.

whereas female rodents were approximately 1.5 times $(\mathrm{AOR}=1.51,95 \% \mathrm{CI}: 1.14-2.01)$ more likely than male rodents to be infected (Table 3 ).

Seoul hantavirus. The overall seroprevalence of Seoul hantavirus in tested rodents was 35.5\%, with $R$. norvegicus (37.5\%) having a higher seroprevalence than $R$. rattus (20.6\%). SEOV seroprevalence ranged between $9.1 \%$ (construction sites) $-46.8 \%$ (industrial areas) for the various landscape structures. In bivariate analyses, SEOV infection was associated with landscape structure, species, sex and weight of rodents (Table 4). Rodents captured in army camps $(\mathrm{OR}=0.47,95 \% \mathrm{CI}: 0.22-0.93)$ and construction sites $(\mathrm{OR}=0.16,95 \% \mathrm{CI}: 0.05-0.41)$ 


\begin{tabular}{|c|c|c|c|}
\hline Explanatory variables & Adjusted odds ratio & 95\% Conf. interval ${ }^{a}$ & $p$-value \\
\hline \multicolumn{4}{|l|}{ Landscape structure } \\
\hline Residential- public ${ }^{\mathrm{b}}$ & Ref & - & - \\
\hline Army camps & 0.33 & $0.12,0.76$ & 0.015 \\
\hline Commercial sites & 2.91 & $1.82,4.68$ & $<0.001$ \\
\hline Construction sites & 0.19 & $0.05,0.54$ & 0.005 \\
\hline Food establishments & 0.55 & $0.29,1.00$ & 0.053 \\
\hline Industrial areas & 1.27 & $0.63,2.29$ & 0.5 \\
\hline Parks & 0.18 & $0.04,0.53$ & 0.006 \\
\hline Residential- private & 0.33 & $0.07,1.10$ & 0.33 \\
\hline Schools $^{c}$ & - & - & - \\
\hline Shipyards & 1.13 & $0.47,2.65$ & 0.8 \\
\hline \multicolumn{4}{|l|}{ Sex } \\
\hline Male $^{\mathrm{b}}$ & Ref & - & - \\
\hline Female & 1.51 & $1.14,2.01$ & 0.004 \\
\hline Weight (g) & 1.010 & $1.009,1.012$ & $<0.001$ \\
\hline
\end{tabular}

Table 3. Multivariable logistic regression model for Leptospira spp. detection in Rattus rattus and Rattus norvegicus. Significant values $(P<0.05)$ are shown in bold. ${ }^{\text {a }} 95 \%$ Confidence Interval. ${ }^{\text {b }}$ Reference category. ${ }^{c}$ Omitted from the model because no Leptospira infection was detected at this site.

\begin{tabular}{|c|c|c|c|}
\hline Explanatory variables & Odds ratio & 95\% Conf. interval ${ }^{a}$ & $p$-value \\
\hline \multicolumn{4}{|l|}{ Landscape structure } \\
\hline Residential- public ${ }^{\mathrm{b}}$ & Ref & - & - \\
\hline Army camps & 0.47 & $0.22,0.93$ & 0.039 \\
\hline Commercial sites & 1.10 & $0.73,1.65$ & 0.6 \\
\hline Construction sites & 0.16 & $0.05,0.41$ & $<0.001$ \\
\hline Food establishments & 0.69 & $0.40,1.15$ & 0.2 \\
\hline Industrial areas & 1.44 & $0.79,2.61$ & 0.2 \\
\hline Parks & 0.55 & $0.23,1.19$ & 0.15 \\
\hline Residential- private & 0.35 & $0.10,0.93$ & 0.056 \\
\hline Schools & 0.18 & $0.01,0.98$ & 0.11 \\
\hline Shipyards & 2.09 & $0.94,4.77$ & 0.073 \\
\hline \multicolumn{4}{|l|}{ Species } \\
\hline Rattus rattus ${ }^{\mathrm{b}}$ & Ref & - & - \\
\hline Rattus norvegicus & 2.34 & $1.52,3.71$ & $<0.001$ \\
\hline \multicolumn{4}{|l|}{ Sex } \\
\hline Male $^{\text {b }}$ & Ref & - & - \\
\hline Female & 1.56 & $1.21,2.01$ & $<0.001$ \\
\hline \multicolumn{4}{|l|}{ Weight (g) } \\
\hline Rattus rattus & 1.02 & $1.01,1.03$ & $<0.001$ \\
\hline Rattus norvegicus & 1.006 & $1.005,1.07$ & $<0.001$ \\
\hline
\end{tabular}

Table 4. Bivariable logistic regression analysis for Seoul hantavirus antibody detection in Rattus rattus and Rattus norvegicus. Significant values $(P<0.05)$ are shown in bold. ${ }^{a} 95 \%$ Confidence Interval. ${ }^{\text {b }}$ Reference category.

showed a reduced prevalence of infection when compared with public residential developments (Table 4). $R$. norvegicus had 2.34 times $(\mathrm{OR}=2.34,95 \% \mathrm{CI}$ : 1.52-3.71) higher likelihood than $R$. rattus to be infected, whereas female rodents were 1.56 times $(\mathrm{OR}=1.56,95 \% \mathrm{CI}$ : $1.21-2.01)$ more likely than male rodents to be infected. The prevalence of SEOV infection increases for every $1 \mathrm{~g}$ increase in body weight for both $R$. rattus $(\mathrm{OR}=1.02,95 \%$ CI: $1.01-1.03$ ) and $R$. norvegicus (OR=1.006, 95\% CI: 1.005-1.07) (Table 4).

Multivariable logistic regression model for SEOV antibody detection in rodents (Table 5) retained the following four variables that were shown to be statistically significant $(P<0.05)$ in the bivariate analysis: landscape structure, species, weight, and sex. Strong association was observed between landscape structure and SEOV infection in trapped rodents, with commercial sites $(\mathrm{AOR}=2.77,95 \% \mathrm{CI}: 1.73-4.44)$ and shipyards (AOR $=6.61,95 \%$ CI: 1.87-24.7) showing an increased prevalence of infection when compared with public residential developments 


\begin{tabular}{|c|c|c|c|}
\hline Explanatory variables & Adjusted odds ratio & 95\% Conf. interval a & $p$-value \\
\hline \multicolumn{4}{|l|}{ Landscape structure } \\
\hline Residential- public ${ }^{\mathrm{b}}$ & Ref & - & - \\
\hline Army camps & 1.82 & $0.63,5.45$ & 0.3 \\
\hline Commercial sites & 2.77 & $1.73,4.44$ & $<0.001$ \\
\hline Construction sites & 0.40 & $0.11,1.12$ & 0.11 \\
\hline Food establishments & 0.80 & $0.44,1.42$ & 0.5 \\
\hline Industrial areas & 1.75 & $0.89,3.42$ & 0.10 \\
\hline Parks & 1.81 & $0.61,5.38$ & 0.3 \\
\hline Residential- private & 0.64 & $0.14,2.18$ & 0.5 \\
\hline Schools & 0.99 & $0.05,7.08$ & $>0.9$ \\
\hline Shipyards & 6.61 & $1.87,24.7$ & 0.004 \\
\hline \multicolumn{4}{|l|}{ Species } \\
\hline Rattus rattus ${ }^{\mathrm{b}}$ & Ref & - & - \\
\hline Rattus norvegicus & 2.62 & $1.02,7.29$ & $0.054^{c}$ \\
\hline \multicolumn{4}{|l|}{ Sex } \\
\hline Male $^{\mathrm{b}}$ & Ref & - & - \\
\hline Female & 1.70 & $1.29,2.25$ & $<0.001$ \\
\hline Weight (g) & 1.007 & $1.006,1.009$ & $<0.001$ \\
\hline
\end{tabular}

Table 5. Multivariable logistic regression model for Seoul hantavirus antibody detection in Rattus rattus and Rattus norvegicus. Significant values $(P<0.05)$ are shown in bold. ${ }^{a} 95 \%$ Confidence Interval. ${ }^{b}$ Reference category. ${ }^{\mathrm{c}}$ Borderline statistical significance.

(Table 5). $R$. norvegicus had 2.62 times (AOR $=2.62,95 \%$ CI: 1.02-7.29) higher likelihood of SEOV infection compared with $R$. rattus, but at a borderline statistical significance $(P=0.054)$. SEOV infection was also independently associated with both the weight and sex of rodents. The prevalence of SEOV infection increases for every $1 \mathrm{~g}$ increase in body weight $(\mathrm{AOR}=1.007,95 \% \mathrm{CI}: 1.006-1.009)$, whereas female rodents were 1.7 times $(\mathrm{AOR}=1.70,95 \% \mathrm{CI}: 1.29-2.25)$ more likely than male rodents to be infected (Table 5).

Rickettsia typhi. The overall seroprevalence of Rickettsia typhi in tested rodents was 32.2\%, with R. norvegicus (32.6\%) showing slightly higher seroprevalence than $R$. rattus (29.8\%).

The lowest seroprevalence of $R$. typhi was found to be in construction sites (9.1\%) and the highest in schools (60\%). In bivariate analyses, $R$. typhi infection was associated with landscape structure and weight of rodents (Table 6). Rodents captured in commercial sites $(\mathrm{OR}=0.28,95 \% \mathrm{CI}: 0.16-0.48)$ and construction sites $(\mathrm{OR}=0.18$, 95\% CI: 0.05-0.45) showed a reduced prevalence of infection, whereas rodents trapped in industrial areas $(\mathrm{OR}=2.05,95 \% \mathrm{CI}: 1.13-3.73)$ and shipyards $(\mathrm{OR}=2.29,95 \% \mathrm{CI}: 1.03-5.24)$ displayed a higher prevalence of infection when compared with public residential developments (Table 6). The prevalence of $R$. typhi infection increases for every $1 \mathrm{~g}$ increase in body weight for both $R$. rattus $(\mathrm{OR}=1.007,95 \% \mathrm{CI}$ : 1.001-1.013) and $R$. norvegicus $(\mathrm{OR}=1.005,95 \% \mathrm{CI}$ : 1.004-1.006) (Table 6). In addition, species and sex of rodents did not influence prevalence of $R$. typhi infection.

Multivariable logistic regression model for R. typhi antibody detection in rodents (Table 7) retained the following two variables that were shown to be statistically significant $(P<0.05)$ in the bivariate analysis: landscape structure and weight. Higher prevalence of $R$. typhi infection was observed in rodents captured in schools $(\mathrm{AOR}=4.10,95 \% \mathrm{CI}: 1.14-16.4)$, industrial sites $(\mathrm{AOR}=2.10,95 \% \mathrm{CI}: 1.13$ to 3.9$)$ and shipyards $(\mathrm{AOR}=2.48$, 95\% CI: 1.08-5.75), whereas rodents trapped in commercial sites ( $\mathrm{AOR}=0.45,95 \% \mathrm{CI}: 0.24-0.77)$ and construction sites $(\mathrm{AOR}=0.26,95 \% \mathrm{CI}: 0.08-0.68)$ presented a lower prevalence when compared to public residential developments (Table 7). The prevalence of $R$. typhi infection also increases for every $1 \mathrm{~g}$ increase in body weight $(\mathrm{AOR}=1.004,95 \% \mathrm{CI}: 1.003-1.005)$. No association was found between $R$. typhi infection and either species or sex of rodents.

Yersinia pestis. Yersinia pestis was not detected in the rodents tested.

\section{Discussion}

Rattus norvegicus and Rattus rattus are the two commonly found rodent species in Singapore. $R$. norvegicus being the dominant species in Singapore, accounted for $86.6 \%$ of our trapped rodents, is also found in Southeast Asia and throughout the world ${ }^{74-77}$. Both species of rodents have adapted to occupy a wide variety of habitats where food and shelter may be found. Our study showed that most of the $R$. norvegicus were trapped in public residential developments (70.6\%), while $R$. rattus were scattered across different urban habitats, with most of the $R$. rattus trapped in army camps $(27.9 \%)$. $R$. norvegicus are good swimmers and their presence are often associated with sewer systems ${ }^{12}$, like those present in public residential developments. On the contrary, $R$. rattus are good climbers, often found in elevated settings such as ceiling and wall cracks of poorly maintained buildings 


\begin{tabular}{|c|c|c|c|}
\hline Explanatory variables & Odds ratio & $95 \%$ Conf. interval $^{a}$ & $p$-value \\
\hline \multicolumn{4}{|l|}{ Landscape structure } \\
\hline Residential- public ${ }^{b}$ & Ref & - & - \\
\hline Army camps & 0.90 & $0.46,1.68$ & 0.7 \\
\hline Commercial sites & 0.28 & $0.16,0.48$ & $<0.001$ \\
\hline Construction sites & 0.18 & $0.05,0.45$ & 0.001 \\
\hline Food establishments & 0.66 & $0.38,1.10$ & 0.12 \\
\hline Industrial areas & 2.05 & $1.13,3.73$ & 0.018 \\
\hline Parks & 0.42 & $0.15,0.96$ & 0.056 \\
\hline Residential- private & 0.50 & $0.16,1.27$ & 0.2 \\
\hline Schools & 2.70 & $0.77,10.7$ & 0.13 \\
\hline Shipyards & 2.29 & $1.03,5.24$ & 0.043 \\
\hline \multicolumn{4}{|l|}{ Species } \\
\hline Rattus rattus ${ }^{\mathrm{b}}$ & Ref & - & - \\
\hline Rattus norvegicus & 1.15 & $0.78,1.73$ & 0.5 \\
\hline \multicolumn{4}{|l|}{ Sex } \\
\hline Male $^{b}$ & Ref & - & - \\
\hline Female & 1.21 & $0.94,1.56$ & 0.14 \\
\hline \multicolumn{4}{|l|}{ Weight (g) } \\
\hline Rattus rattus & 1.007 & $1.001,1.013$ & 0.035 \\
\hline Rattus norvegicus & 1.005 & $1.004,1.006$ & $<0.001$ \\
\hline
\end{tabular}

Table 6. Bivariable logistic regression analysis for Rickettsia typhi antibody detection in Rattus rattus and Rattus norvegicus. Significant values $(P<0.05)$ are shown in bold. ${ }^{a} 95 \%$ Confidence Interval. ${ }^{\text {b }}$ Reference category.

\begin{tabular}{|l|l|l|l|}
\hline Explanatory variables & Adjusted odds ratio & 95\% Conf. interval ${ }^{\text {a }}$ & p-value $^{|l|}$ \\
\hline Landscape structure & \multicolumn{4}{l|}{} \\
\hline Residential- public ${ }^{\text {b }}$ & Ref & - & - \\
\hline Army camps & 1.27 & $0.64,2.41$ & 0.5 \\
\hline Commercial sites & 0.45 & $0.24,0.77$ & $\mathbf{0 . 0 0 6}$ \\
\hline Construction sites & 0.26 & $0.08,0.68$ & $\mathbf{0 . 0 1 3}$ \\
\hline Food establishments & 0.72 & $0.40,1.23$ & 0.2 \\
\hline Industrial areas & 2.10 & $1.13,3.90$ & $\mathbf{0 . 0 1 8}$ \\
\hline Parks & 0.63 & $0.23,1.50$ & 0.3 \\
\hline Residential- private & 0.71 & $0.23,1.84$ & 0.5 \\
\hline Schools & 4.10 & $1.14,16.4$ & $\mathbf{0 . 0 3 3}$ \\
\hline Shipyards & 2.48 & $1.08,5.75$ & $\mathbf{0 . 0 3 1}$ \\
\hline Weight (g) & 1.004 & $1.003,1.005$ & $<\mathbf{0 . 0 0 1}$ \\
\hline
\end{tabular}

Table 7. Multivariable logistic regression model for Rickettsia typhi antibody detection in Rattus rattus and Rattus norvegicus. Significant values $(P<0.05)$ are shown in bold. ${ }^{a} 95 \%$ Confidence Interval. ${ }^{\text {b }}$ Reference category.

and trees ${ }^{12,18}$, indicating that army camps may present the suitable environmental features favouring $R$. rattus. This confirmed the differential habitat preferences of $R$. norvegicus and $R$. rattus, with $R$. norvegicus preferring wet habitats, and $R$. rattus favouring drier habitats ${ }^{15,19}$.

This study revealed the presence of three rodent-borne pathogens: Leptospira spp., Seoul hantavirus and Rickettsia typhi in Singapore's rodent population. Studies have shown that urban landscapes provide opportunities for increased rodent density ${ }^{78,79}$ and circulation of pathogens ${ }^{80}$. In addition, our study discovered that certain landscapes and environmental factors were associated with an increased probability of rodent infestation and occurrence of pathogens than others. Public residential developments in particular presented a concerning issue as shown by the large number of captured and infected rodents in the vicinity. This could pose a potential risk of transmitting diseases to humans, as these residential developments provided habitat and environmental features that encouraged rodents to feed and breed in close proximity to the human population.

Public residential development is one of the landscape structures with high population density, as more than $80 \%$ of Singapore's population resides within these areas ${ }^{81}$. These high-rise buildings have a centralised rubbish chute system whereby rubbish is dropped into a large collection bin at the bottom of the refuse chute. Rodents 
could gain access to these bins through broken gully traps connected to the sewer system ${ }^{82}$. Accessible garbage through faulty gully traps has been identified as an environmental factor associated with rodent infestations ${ }^{12}$. Rodents congregating at these areas that provide shelter, water and food create opportunities for direct and indirect transmission of pathogens within the rodent population.

Chronically infected rodents are asymptomatic, and they can shed pathogenic Leptospira spp. and SEOV into the environment through their urine ${ }^{3,83-86}$. Outside a host, these pathogens thrive in the warm and moist surroundings, contaminating rodents' living spaces including their food and water sources ${ }^{87,88}$. Transmission between rodents may also occur through direct contact with an infected rodent during social interactions such as grooming ${ }^{84,89}$ or fighting ${ }^{3,74,90}$, with the latter resulting in open wounds which can be infected by the contaminated environment. Garbage dumps and sewers are some of the habitats favoured by $R$. norvegicus, explaining the strong association between $R$. norvegicus and increased prevalence of Leptospira spp. and SEOV infections. These findings are in agreement with previous studies showing a high Leptospira spp. prevalence in $R$. norvegicus compared with $R$. rattus ${ }^{91,92}$.

Unlike SEOV and Leptospira spp., R. typhi is primarily transmitted by the Oriental rat flea (Xenopsylla cheo$p i s)$. Fleas become infected when they feed on an infected rodent hos $\mathrm{t}^{21}$. As fleas usually feed and defecate at the same time, infected fleas feeding on other rodents and rubbing the infected flea faeces into the bite wounds or other wounds, could spread R. typhi to them ${ }^{21}$. Interestingly, our study revealed that $90 \%$ of the rodents caught in schools were $R$. rattus, and they had the highest likelihood of $R$. typhi infection, but not Leptospira spp. nor SEOV infection. On the other hand, $100 \%$ of the rodents caught in shipyards were also $R$. rattus, but they have been associated with an increased prevalence of both SEOV and R. typhi infections. Other than the presence of both fleas as vectors and rodents serving as hosts for $R$. typhi transmission, further investigation on the microenvironmental factors will be required to provide insight into environmental features conducive for transmission of $R$. typhi. It is also crucial to examine the habitats of $R$. rattus in shipyards to identify the factors promoting the circulation of rodent-borne pathogens.

Singapore reported that construction labourers accounted for $49 \%$ of the locally acquired human leptospirosis cases from 2012 to 2015 and a large proportion of the local murine typhus cases ${ }^{53,93}$. Construction workers are prone to sustain skin abrasions, which may increase the risk of infection. However, our study showed that the rodents trapped in construction sites had one of the lowest prevalence of Leptospira spp., SEOV and R. typhi infections. Therefore, both the occupational and non-occupational environments of the construction workers should be considered when determining the environmental factors associated with pathogen exposure risk. Housing types available for construction workers include temporary structures at construction sites, such as construction temporary quarters (CTQs), or a more long-term housing such as quick-build dormitories (QBDs) or purpose-built dormitories (PBDs $)^{94}$. The temporary living quarters provided for the construction workers are often overcrowded, unhygienic and infested with rodents $s^{53}$. Rodent trapping and sampling at workers' housing with suboptimal living conditions will be included in our future studies for better surveillance and interventions.

Previous studies have shown that male rodents had a higher chance of getting infected than female rodents as male rodents were more likely to engage in aggressive interactions than female rodents ${ }^{88,95}$. Other studies suggested that female rodents were more prone to infection, while some argued that both sexes were equally susceptible to possible infections ${ }^{15,84}$. In contrast, our study found higher prevalence of Leptospira spp. and SEOV infections in female rodents, while no difference in the prevalence of $R$. typhi infection was observed between the sexes. These conflicting research evidence may be hinting that the prevalence of infection could be more closely associated with habitat conducive for the transmission of pathogens, where both sexes are equally exposed to possible infections, than sex differences.

We reported that the increasing weight of rodents was strongly associated with prevalence of rodents being infected with any of the three rodent-borne pathogens. Our findings are consistent with previous reports stating that social and hierarchical interactions within the colony and exploratory behaviour of larger rodents ${ }^{75}$ could $^{8}$ increase transmission events of these pathogens ${ }^{15,76}$. However, no clear association between weight of rodents and prevalence of $R$. typhi infection was observed in a previous study carried out in Baltimore, USA ${ }^{96}$. These discrepancies highlight that the risk factors had a varying extent of influence on prevalence of infection, and that it is important to consider the habitat and behaviour of rodents when determining the likelihood of infection.

When we compare to other urban rodent studies, the seroprevalence of $R$. typhi (32.2\%) in tested rodents was similar to that in Jakarta, Indonesia $(38.5 \%)^{97}$, but higher than that in Spain $(21.2 \%)^{98}$. The seroprevalence of SEOV amongst the rodents was slightly higher (35.5\%) than what was previously reported (26\%) in a serosurvey conducted in Singapore in $1989^{7}$. Leptospira spp. was detected in over $40 \%$ of the rodents sampled, lower than that reported in Brazil ${ }^{28}$, but higher than that reported in Tokyo, Japan ${ }^{99}$. Despite having high prevalence of Leptospira spp., SEOV and $R$. typhi infections in Singapore's rodent population, the reported annual incidences of the diseases in humans caused by these rodent-borne pathogens are relatively low. This could be attributed to the relative infrequent occurrence of rodents within residential homes compared to that on the streets which may reduce human-rodent contact and hence reduce the risk of acquiring the diseases ${ }^{100}$.

The main limitation of the study was sampling bias due to the use of opportunistic sampling strategy, which could lead to an over- or under-estimation of the pathogen prevalence. Moreover, opportunistic sampling reduced our ability to estimate rodent infestation rates at the different landscape structures, which would have strengthened our findings. The dominant pathogenic and/or intermediate Leptospira species circulating in Singapore's rodent population was also not elucidated. This information is critical in understanding the epidemiology of leptospirosis which is the relationship between prevalent Leptospira species and the species of rodent reservoirs and their habitats. In addition, the prevalence of SEOV and $R$. typhi infections were determined by detecting pathogen-specific antibodies, and the respective pathogen genomes were not amplified. The current infection status of the rodents cannot be determined, as being seropositive for Seoul hantavirus and R. typhi could be due to previous infections. As a result, the pathogen load in our rodent samples cannot be determined. Rodent 
density and pathogen load are necessary to evaluate the degree of potential environmental contamination in an urban ecosystem, which would then influence the risk of human exposure, and the likelihood of transmitting rodent-borne diseases to humans within the shared environment. Further investigations are necessary to fully understand the role of rodents in disease transmission in their urban habitats and the impact on public health.

Yersinia pestis was not detected amongst the rodent population. Plague is not endemic to our nation and an article published in 1900 documented the introduction of plague to Singapore through trading port ${ }^{101}$. With strict preventive measures at our port, we prevented local transmission of Yersinia pestis. Nonetheless, Singapore remains vulnerable to the sporadic importation of Yersinia pestis, and constant vigilance is necessary.

\section{Conclusions}

This study provides valuable insights on the presence of three rodent-borne pathogens in Singapore and their association with different landscape structures. R. norvegicus is the most dominant species in Singapore and is the most important reservoir for Leptospira spp. Rodents caught in public residential developments were the main interest as the habitat provided conducive conditions that contributed to an increased in rodent density and circulation of rodent-borne diseases in rodent population. Rodent infestation in close proximity to dense human settlements increases the risk of transmission of rodent-borne diseases to humans. Future studies focusing on the microenvironmental factors of individual urban landscape structures may reveal the determining factors associated with the circulation of pathogens in Singapore's rodent population. Rodent management and sanitation strategies should be deployed to prevent further circulation of the pathogens among rodents and safeguard against transmission to human population.

Received: 16 August 2021; Accepted: 10 December 2021

Published online: 17 February 2022

\section{References}

1. Meerburg, B. G., Singleton, G. R. \& Kijlstra, A. Rodent-borne diseases and their risks for public health. Crit. Rev. Microbiol. 35, 221-270 (2009).

2. Ermonval, M., Baychelier, F. \& Tordo, N. What do we know about how hantaviruses interact with their different hosts?. Viruses 8, 223 (2016).

3. Costa, F. et al. Patterns in leptospira shedding in Norway Rats (Rattus norvegicus) from Brazilian slum communities at high risk of disease transmission. PLoS Negl. Trop. Dis. 9, e0003819. https://doi.org/10.1371/journal.pntd.0003819 (2015).

4. Aung, A. K., Spelman, D. W., Murray, R. J. \& Graves, S. Rickettsial infections in Southeast Asia: implications for local populace and febrile returned travelers. Am. J. Trop. Med. Hyg. 91, 451-460 (2014).

5. Prendergast, M. E. et al. Reconstructing Asian faunal introductions to eastern Africa from multi-proxy biomolecular and archaeological datasets. PLoS ONE 12(8), e0182565 (2017).

6. Puckett, E. E. \& Munshi-South, J. Brown rat demography reveals pre-commensal structure in eastern Asia before expansion into Southeast Asia. Genome Res. 29, 762-770 (2019).

7. Zeng, L. et al. Out of southern East Asia of the brown rat revealed by large-scale genome sequencing. Mol. Biol. Evol. 35, 149-158. https://doi.org/10.1093/molbev/msx276 (2018).

8. Aplin, K. P. et al. Multiple geographic origins of commensalism and complex dispersal history of Black Rats. PLoS ONE 6, e26357. https://doi.org/10.1371/journal.pone.0026357 (2011).

9. Lund, M. Commensal rodents. (1994).

10. Buckle, A. P. \& Smith, R. H. Rodent pests and their control (CABI, Wallingford, 2015).

11. Assefa, A. \& Chelmala, S. Comparison of rodent community between natural and modified habitats in Kafta-Sheraro National Park and its adjoining villages, Ethiopia: implication for conservation. J. Basic Appl. Zool. 80, 59 (2019).

12. de Masi, E., Vilaca, P. \& Razzolini, M. T. Environmental conditions and rodent infestation in Campo Limpo district, Sao Paulo municipality Brazil. Int. J. Environ. Health Res. 19, 1-16. https://doi.org/10.1080/09603120802126670 (2009).

13. Morand, S. et al. Assessing the distribution of disease-bearing rodents in human-modified tropical landscapes. J. Appl. Ecol. 52, 784-794 (2015).

14. Statistics times. List of countries by population density, <http://statisticstimes.com/demographics/countries-by-population-densi ty.php> (2019).

15. Krojgaard, L. H. et al. High prevalence of Leptospira spp. in sewer rats (Rattus norvegicus). Epidemiol. Infect. 137, 1586-1592. https://doi.org/10.1017/S0950268809002647 (2009).

16. Brooks, J. E. \& Jackson, W. B. A review of commensal rodents and their control. CRC Crit. Rev. Environ. Control. 3, 405-453 (1973).

17. Pisano, R. G. \& Storer, T. I. Burrows and feeding of the Norway rat. J. Mammal. 29, 374-383 (1948).

18. Foster, S., King, C., Patty, B. \& Miller, S. Tree-climbing capabilities of Norway and ship rats. N. Z. J. Zool. 38, 285-296. https:// doi.org/10.1080/03014223.2011.599400 (2011).

19. Husson, A. M. The Mammals of Suriname. Zoölogische Monographieën 2, 3-569 (1978).

20. Gerozisis, J., Hadlington, P. W. \& Staunton, I. Urban pest management in Australia (UNSW Press, Randwick, 2008).

21. Azad, A. F. Epidemiology of murine typhus. Ann. Rev. Entomol. 35, 553-569. https://doi.org/10.1146/annurev.en.35.010190. $003005(1990)$

22. Bi, Z. Q., Formenty, P. B. H. \& Roth, C. E. Hantavirus Infection: a review and global update. J. Infect. Dev. Ctries. 2, 3-23 (2008).

23. Bharti, A. R. et al. Leptospirosis: a zoonotic disease of global importance. Lancet Infect. Dis. 3, 757-771. https://doi.org/10.1016/ s1473-3099(03)00830-2 (2003).

24. Cohn, S. K. Jr. Epidemiology of the Black Death and successive waves of plague. Med. Hist. Suppl. 5(S27), 74-100 (2008).

25. Wong, T. W. et al. Hantavirus infections in humans and commensal rodents in Singapore. Trans. R. Soc. Trop. Med. Hyg. 83, 248-251 (1989).

26. Levett, P. N. Leptospirosis. Clin. Microbiol. Rev. 14, 296-326. https://doi.org/10.1128/CMR.14.2.296-326.2001 (2001).

27. Bunnag, T., Potha, U., Thirachandra, S. \& Impand, P. Leptospirosis in man and rodents in North and Northeast Thailand. Southeast Asian J. Trop. Med. Publ. Health 14, 481-487 (1983).

28. de Faria, M. T. et al. Carriage of Leptospira interrogans among domestic rats from an urban setting highly endemic for leptospirosis in Brazil. Acta Trop. 108, 1-5. https://doi.org/10.1016/j.actatropica.2008.07.005 (2008).

29. Gollop, J. H., Katz, A. R., Rudoy, R. C. \& Sasaki, D. M. Rat-bite leptospirosis. West J. Med. 159, 76-77 (1993).

30. Abd Rahman, A. N., Hasnul Hadi, N. H., Sun, Z., Thilakavathy, K. \& Joseph, N. Regional prevalence of intermediate Leptospira spp. in humans: a meta-analysis. Pathogens https://doi.org/10.3390/pathogens10080943 (2021). 
31. Philip, N. et al. Leptospira interrogans and Leptospira kirschneri are the dominant Leptospira species causing human leptospirosis in Central Malaysia. PLoS Negl. Trop. Dis. 14, e0008197. https://doi.org/10.1371/journal.pntd.0008197 (2020).

32. Dupont, H. et al. Leptospirosis: prognostic factors associated with mortality. Clin. Infect. Dis. 25, 720-724 (1997).

33. Daher, E., Zanetta, D. M., Cavalcante, M. B. \& Abdulkader, R. C. Risk factors for death and changing patterns in leptospirosis acute renal failure. Am. J. Trop. Med. Hyg. 61, 630-634 (1999).

34. Abgueguen, P. et al. Clinical aspects and prognostic factors of leptospirosis in adults. Retrospective study in France. J. Infect. 57, 171-178. https://doi.org/10.1016/j.jinf.2008.06.010 (2008).

35. Tow, C. et al. in Epidemiological News Bulletin Quarterly Vol. 42 116-122 (Ministry of Health, Singapore, Singapore, 2016).

36. Chan, O. Y., Chia, S. E., Nadarajah, N. \& Sng, E. H. Leptospirosis risk in public cleansing and sewer workers. Ann. Acad. Med. Singap. 16, 586-590 (1987).

37. Chan, O. Y., Paul, D. R. \& Sng, E. H. Leptospirosis among abattoir workers-a serological survey. Singap. Med. J. 28, 293-296 (1987).

38. Lee, H. W. Epidemiology and pathogenesis of haemorrhagic fever with renal syndrome. In The Bunyaviridae (ed. Elliot, R. M.) 253-267 (Plenum Press, 1996).

39. Zhang, S. et al. Epidemic characteristics of hemorrhagic fever with renal syndrome in China, 2006-2012. BMC Infect. Dis. 14, 384 (2014).

40. Kurucz, K. et al. Parallel survey of two widespread renal syndrome-causing zoonoses: Leptospira spp. and Hantavirus in urban environment Hungary. Vector-Borne Zoonotic Dis. 18, 200-205 (2018).

41. Lee, H. W., Baek, L. J. \& Johnson, K. M. Isolation of Hantaan virus, the etiologic agent of Korean hemorrhagic fever, from wild urban rats. J. Infect. Dis. 146, 638-644. https://doi.org/10.1093/infdis/146.5.638 (1982).

42. Kim, Y. S. et al. Hemorrhagic fever with renal syndrome caused by the Seoul virus. Nephron 71, 419-427. https://doi.org/10. 1159/000188762 (1995).

43. Chan, Y. C. et al. Haemorrhagic fever with renal syndrome involving the liver. Med. J. Aust. 147, 248-249 (1987).

44. Chan, K. P., Chan, Y. C. \& Doraisingham, S. A severe case of hemorrhagic fever with renal syndrome in Singapore. Southeast Asian J. Trop. Med. Public. Health 27, 408-410 (1996).

45. Sin, M. A. et al. Risk factors for hantavirus infection in Germany, 2005. Emerg. Infect. Dis. 13, 1364 (2007)

46. Cortes, L. F. L. et al. Murine typhus: clinical and serological review of 42 cases. Med. Clin. (Barc) 81, 835-838 (1983).

47. Silpapojakul, K., Chayakul, P. \& Krisanapan, S. Murine typhus in Thailand: clinical features, diagnosis and treatment. Q J. Med. 86, 43-47 (1993).

48. Azad, A. F. \& Emala, M. A. Suppression of Rickettsia typhi transmission in fleas maintained on murine typhus-immune rats. Am. J. Trop. Med. Hyg 37, 629-635 (1987).

49. Vaughan, J. A. \& Azad, A. F. Acquisition of murine typhus rickettsiae by fleas. Ann. N. Y. Acad. Sci. 590, 70-75 (1990).

50. Azad, A. F., Radulovic, S., Higgins, J. A., Noden, B. H. \& Troyer, J. M. Flea-borne rickettsioses: ecologic considerations. Emerg. Infect. Dis. 3, 319-327 (1997).

51. Ministry of Health. Communicable Diseases Surveillance in Singapore 2003, Vector-borne diseases. (2004).

52. Loh, K. C., Leo, Y. S., Heng, M. K. \& Goh, B. C. Murine typhus: a forgotten cause of febrile illness in Singapore. Singap. Med J 37, 39-43 (1996).

53. Chen, M. I., Chua, J. K., Lee, C. C., Leo, Y. S. \& Kumarasinghe, G. Epidemiological, clinical and laboratory characteristics of 19 serologically confirmed rickettsial disease in Singapore. Singap. Med. J. 42, 553-558 (2001).

54. Fact Sheet- Plague, <http://www.who.int/mediacentre/factsheets/fs267/en/> (2017).

55. Emergencies preparedness, response. Plague-Madagascar disease outbreak news, $<\mathrm{http} / /$ www.who.int/csr/don/27-november-201plague-madagascar/en/> (2017)

56. Samia, N. I. et al. Dynamics of the plague-wildlife-human system in Central Asia are controlled by two epidemiological thresholds. Proc. Natl. Acad. Sci. 108, 14527-14532 (2011).

57. Whiteford, S. F., Taylor, J. P. \& Dumler, J. S. Clinical, laboratory, and epidemiologic features of murine typhus in 97 Texas children. Arch. Pediatr. Adolesc. Med. 155, 396-400 (2001).

58. Silpapojakul, K., Mitarnun, W., Ovartlarnporn, B., Chamroonkul, N. \& Khow-Ean, U. Liver involvement in murine typhus. QJM 89, 623-629 (1996).

59. Kobayashi, Y. Clinical observation and treatment of leptospirosis. J. Infect. Chemother. 7, 59-68. https://doi.org/10.1007/s1015 610070059 (2001).

60. Clement, J. P. Hantavirus. Antiviral Res. 57, 121-127 (2003).

61. Clement, J., Neild, G., Hinrichsen, S. L., Crescente, J. A. \& Van Ranst, M. Urban leptospirosis versus urban hantavirus infection in Brazil. Lancet 354, 2003-2004. https://doi.org/10.1016/S0140-6736(05)76782-9 (1999).

62. Matisoo-Smith, L. No hea te kiore: MtDNA variation in Rattus exulans: a model for human colonisation and contact in prehistoric Polynesia, ResearchSpace@ Auckland (1996).

63. Matisoo-Smith, E. \& Allen, J. S. Name that rat: molecular and morphological identification of pacific rodent remains. Int. J. Osteoarchaeol. 11, 34-42 (2001).

64. Smythe, L. D. et al. A quantitative PCR (TaqMan) assay for pathogenic Leptospira spp. BMC Infect. Dis. 2, 13. https://doi.org/ 10.1186/1471-2334-2-13 (2002).

65. Villumsen, S. et al. Novel TaqMan(R) PCR for detection of Leptospira species in urine and blood: pit-falls of in silico validation. J. Microbiol. Methods 91, 184-190. https://doi.org/10.1016/j.mimet.2012.06.009 (2012).

66. Johansson, P. et al. Molecular characterization of two hantavirus strains from different rattus species in Singapore. Virol. J. 7, 15. https://doi.org/10.1186/1743-422X-7-15 (2010).

67. Razanskiene, A. et al. High yields of stable and highly pure nucleocapsid proteins of different hantaviruses can be generated in the yeast Saccharomyces cerevisiae. J. Biotechnol. 111, 319-333. https://doi.org/10.1016/j.jbiotec.2004.04.010 (2004).

68. Bozeman, F. M. \& Elisberg, B. L. Serological diagnosis of scrub typhus by indirect immunofluorescence. Proc. Soc. Exp. Biol. Med. 112, 568-573 (1963).

69. Radnedge, L., Gamez-Chin, S., McCready, P. M., Worsham, P. L. \& Andersen, G. L. Identification of nucleotide sequences for the specific and rapid detection of Yersinia pestis. Appl. Environ. Microbiol. 67, 3759-3762. https://doi.org/10.1128/AEM.67.8. 3759-3762.2001 (2001).

70. Maurice Burton, R. B. Brown Rat. Vol. 3 298-299 (Marshall Cavendish Corporation, 2010).

71. Yamaoka, K., Nakagawa, T. \& Uno, T. Application of Akaike's information criterion (AIC) in the evaluation of linear pharmacokinetic equations. J. Pharmacokinet. Biopharm. 6, 165-175 (1978).

72. Fox, J. \& Monette, G. Generalized collinearity diagnostics. J. Am. Stat. Assoc. 87, 178-183. https://doi.org/10.2307/2290467 (1992).

73. Murage, P., Hajat, S. \& Kovats, R. S. Effect of night-time temperatures on cause and age-specific mortality in London. Environ. Epidemiol. 1, e005. https://doi.org/10.1097/EE9.0000000000000005 (2017).

74. Himsworth, C. G. et al. Ecology of Leptospira interrogans in Norway rats (Rattus norvegicus) in an inner-city neighborhood of Vancouver, Canada. PLoS Negl. Trop. Dis. 7, e2270. https://doi.org/10.1371/journal.pntd.0002270 (2013).

75. Barnett, S. A. \& Spencer, M. M. Feeding, social behavior and interspecific competition in wild rats. Behaviour 3, 229-242 (1951). 
76. Cueto, G. R., Cavia, R., Bellomo, C., Padula, P. J. \& Suarez, O. V. Prevalence of hantavirus infection in wild Rattus norvegicus and R. rattus populations of Buenos Aires City, Argentina. Trop. Med. Int. Health 13, 46-51. https://doi.org/10.1111/j.1365-3156. 2007.01968.x (2008).

77. Panti-May, J. A. et al. A Two-Year Ecological Study of Norway Rats (Rattus norvegicus) in a Brazilian Urban Slum. PLoS ONE 11, e0152511. https://doi.org/10.1371/journal.pone.0152511 (2016).

78. De Oliveira, R. C. et al. Hantavirus reservoirs: current status with an emphasis on data from Brazil. Viruses 6, 1929-1973 (2014).

79. Himsworth, C. G., Jardine, C. M., Parsons, K. L., Feng, A. Y. \& Patrick, D. M. The characteristics of wild rat (Rattus spp.) populations from an inner-city neighborhood with a focus on factors critical to the understanding of rat-associated zoonoses. PLoS ONE 9(3), e91654 (2014).

80. Patz, J. A. et al. Unhealthy landscapes: policy recommendations on land use change and infectious disease emergence. Environ. Health Perspect. 112, 1092-1098 (2004).

81. Data.gov.sg. Estimated Singapore resident population in HDB flats, <https://data.gov.sg/dataset/estimated-resident-populationliving-in-hdb-flats?view_id=d9174d5e-e811-4235-b150-feb869falf49\&resource_id=a7d9516f-b193-4f9b-8bbf-9c85a4c9b61b> (2020).

82. Tan, A. in The Straits Times (Singapore, 2016, August 17).

83. Minter, A. et al. A model for leptospire dynamics and control in the Norway rat (Rattus norvegicus) the reservoir host in urban slum environments. Epidemics 25, 26-34. https://doi.org/10.1016/j.epidem.2018.05.002 (2018).

84. Minter, A. et al. Evidence of multiple intraspecific transmission routes for Leptospira acquisition in Norway rats (Rattus norvegicus). Epidemiol. Infect. 145, 3438-3448. https://doi.org/10.1017/S0950268817002539 (2017).

85. Kariwa, H. et al. Urine-associated horizontal transmission of Seoul virus among rats. Adv. Virol. 143, 365-374 (1998).

86. Thiermann, A. B. The Norway rat as a selective chronic carrier of Leptospira icterohaemorrhagiae1. J. Wildl. Dis. 17, 39-43. https://doi.org/10.7589/0090-3558-17.1.39 (1981).

87. Hartskeerl, R. A., Collares-Pereira, M. \& Ellis, W. A. Emergence, control and re-emerging leptospirosis: dynamics of infection in the changing world. Clin. Microbiol. Infect. 17, 494-501. https://doi.org/10.1111/j.1469-0691.2011.03474.x (2011).

88. Khalil, H. et al. Dynamics and drivers of hantavirus prevalence in rodent populations. Vector Borne Zoonotic Dis. 14, 537-551. https://doi.org/10.1089/vbz.2013.1562 (2014).

89. Hinson, E. R., Shone, S. M., Zink, M. C., Glass, G. E. \& Klein, S. L. Wounding: the primary mode of Seoul virus transmission among male Norway rats. Am. J. Trop. Med. Hyg. 70, 310-317 (2004).

90. Costa, F. et al. Infections by Leptospira interrogans, Seoul virus, and Bartonella spp. among Norway rats (Rattus norvegicus) from the urban slum environment in Brazil. Vector Borne Zoonotic Dis. 14, 33-40. https://doi.org/10.1089/vbz.2013.1378 (2014).

91. Houemenou, G., Ahmed, A., Libois, R. \& Hartskeerl, R. A. Leptospira spp. prevalence in small mammal populations in Cotonou Benin. ISRN Epidemiol. 2013, 8. https://doi.org/10.5402/2013/502638 (2013).

92. Perez, J., Brescia, F., Becam, J., Mauron, C. \& Goarant, C. Rodent abundance dynamics and leptospirosis carriage in an area of hyper-endemicity in New Caledonia. PLoS Negl. Trop. Dis. 5, e1361-e1361. https://doi.org/10.1371/journal.pntd.0001361 (2011).

93. Health, M. O. (Ministry of Health, Singapore, Singapore, 2017).

94. Various types of housing and their specific requirements, <https://www.mom.gov.sg/passes-and-permits/work-permit-for-forei gn-worker/housing/various-types-of-housing > (2021).

95. Cosson, J. F. et al. Epidemiology of leptospira transmitted by rodents in southeast Asia. PLoS Negl. Trop. Dis. 8, e2902. https:// doi.org/10.1371/journal.pntd.0002902 (2014).

96. Easterbrook, J. D. et al. A survey of zoonotic pathogens carried by Norway rats in Baltimore, Maryland, USA. Epidemiol. Infect. 135, 1192-1199 (2007).

97. Ibrahim, I. N. et al. Serosurvey of wild rodents for Rickettsioses (spotted fever, murine typhus and Q fever) in Java Island, Indonesia. Eur. J. Epidemiol. 15, 89-93. https://doi.org/10.1023/a:1007547721171 (1999).

98. Lledó, L. et al. Rickettsia typhi infection in wild rodents from central Spain. Ann. Trop. Med. Parasitol. 97, 411-414 (2003).

99. Koizumi, N. et al. Human leptospirosis cases and the prevalence of rats harbouring Leptospira interrogans in urban areas of Tokyo, Japan. J. Med. Microbiol. 58, 1227-1230. https://doi.org/10.1099/jmm.0.011528-0 (2009).

100. Childs, J. E. et al. Human-rodent contact and infection with lymphocytic choriomeningitis and Seoul viruses in an inner-city population. Am. J. Trop. Med. Hyg. 44, 117-121 (1991).

101. Simon, M. Plague in relation to Singapore. Lancet 155, 153-155. https://doi.org/10.1016/S0140-6736(01)87426-2 (1900).

\section{Acknowledgements}

We would like to thank Singapore Pest Management Association who assisted in rodent trappings, as well as our colleagues at DSO National Laboratories and National Environment Agency for their technical support.

\section{Author contributions}

G.Y., D.M., P.J., C.C.S., P.L. and L.C.N. conceived and designed the experiments. G.Y., P.J., H.T.L., C.C.S. and L.C.N. performed the experiments. J.G., H.L.Y. and D.M. analysed the data. J.G. and H.L.Y. wrote the manuscript, with active inputs from D.M. and L.C.N.. All authors read and approved the final manuscript.

\section{Funding}

This study was financially supported by Ministry of Environment and Water Resources (Singapore), and the Future Systems and Technology Directorate, Ministry of Defence.

\section{Competing interests}

The authors declare no competing interests.

\section{Additional information}

Correspondence and requests for materials should be addressed to H.L.Y. or L.C.N.

Reprints and permissions information is available at www.nature.com/reprints.

Publisher's note Springer Nature remains neutral with regard to jurisdictional claims in published maps and institutional affiliations. 
(c) (i) Open Access This article is licensed under a Creative Commons Attribution 4.0 International cc) License, which permits use, sharing, adaptation, distribution and reproduction in any medium or format, as long as you give appropriate credit to the original author(s) and the source, provide a link to the Creative Commons licence, and indicate if changes were made. The images or other third party material in this article are included in the article's Creative Commons licence, unless indicated otherwise in a credit line to the material. If material is not included in the article's Creative Commons licence and your intended use is not permitted by statutory regulation or exceeds the permitted use, you will need to obtain permission directly from the copyright holder. To view a copy of this licence, visit http://creativecommons.org/licenses/by/4.0/.

(C) The Author(s) 2022 